Research Article

\title{
Seismic Behavior Analysis of Recycled Aggregate Concrete-filled Steel Tube Column
}

\author{
Zhang Xianggang ${ }^{1}$, Wang Shuren ${ }^{1,2,3^{*}}$, Gao Xiang ${ }^{1}$ and He Yongsheng ${ }^{4}$ \\ ${ }^{I}$ School of Civil Engineering, Henan Polytechnic University, Jiaozuo 454003, China \\ ${ }^{2}$ International Joint Research Laboratory of Henan Province for Underground Space Development and Disaster Prevention, Henan \\ Polytechnic University, Jiaozuo 454003, China \\ ${ }^{3}$ School of Minerals and Energy Resources Engineering, University of New South Wales, Sydney, NSW 2052, Australia \\ ${ }^{4}$ Institute of National Defense Engineering, Academy of Military Sciences, Luoyang 471023, China
}

Received 10 May 2019; Accepted 27 August 2019

\begin{abstract}
To investigate the seismic behavior of recycled aggregate concrete-filled circular steel tube (C-RACFST), twenty-three full-scale specimens were tested by changing the design parameters. Seismic behavior indices, such as hysteresis curve, skeleton curve, ductility coefficient, and energy dissipation capacity were analyzed and the influence rules of design parameters on seismic behavior index were revealed. Results show that it is feasible to apply C-RACFST to the actual load-bearing structure based on the seismic behavior index requirements. With the increase of the steel ratio, the hysteresis curve become plumper, and the peak-bearing capacity and displacement ductility coefficient increase. With the increase of the axial compression ratio, the peak-bearing capacity and ductility decrease and the energy dissipation coefficient of each specimen increases gradually under the same cycle displacement. The conclusions obtained in the study are of reference value to direct the similar engineering.
\end{abstract}

Keywords: Concrete-filled circular steel tube, Full-scale specimen, Design parameters, Seismic behavior

\section{Introduction}

Recycled aggregate concrete (RAC) technology has become a hotspot and frontier topic in engineering and academic circles [1]. However, the limitations of RAC, such as large water absorption, large pores, low strength and elastic modulus, and poor fluidity, hinder its application in engineering practice [2]. So, the combination structure of recycled aggregate concrete-filled steel tube (RACFST) came into being.

The interaction between the steel tube and RAC in the loading process has improved the mechanical properties of the latter and conferred respective mechanical advantage [3]. The circular RACFST (C-RACFST) column has better restraint than the square column on the internal RAC and which exhibits satisfactory seismic behavior. The new composite structure shows excellent application prospects in single- and multistorey industrial buildings, large-span and space structures, commercial plazas, and residential buildings in the seismic fortification zone [4].

To investigate the seismic behavior of recycled aggregate concrete-filled circular steel tube (C-RACFST) to avoid some negative effects on the basic physical and mechanical properties of C-RACFST, which is of the reference value for the practical engineering.

\section{State of the Art}

As it is well known, the RACFST structure was proposed based on concrete-filled steel tube (CFST) structure, and the

*E-mail address: w_sr88@163.com

ISSN: 1791-2377 @ 2019 School of Science, IHU. All rights reserved.

doi:10.25103/iestr.124.16 research of CFST structure was expanded to the RACFST structure. Al-Eliwi et al. studied the axial compression performance of the reinforced lightweight aggregate concrete-filled circular steel tube columns and found that the existence of steel-bar reinforcement improved the bearing capacity, ductility and toughness of the columns [5]. Nabati et al. conducted the axial compression test on the CFRPreinforced concrete-filled steel tubes and they found that the bearing capacity mainly depended on the grade of concrete and steel used in the composite column [6]. Pons et al. analyzed the mechanical performance of ultra-high concretefilled circular steel columns under concentric axial forces and found that the three-dimension numerical results were in good agreement with the experimental results [7].

As for RACFST structure, the compressive behavior was one of the primary mechanical types. Choi researched the axial compression performance of RACFST specimens and found that RACFST could be applied to real buildings by making high strength RAC [8]. Abed et al. studied the compressive performance of circular CFST column and found that the axial bearing capacity increased and decreased with the increase of the concrete compressive strength and diameter-thickness ratio, respectively [9]. Mohanraj et al. conducted the axial compression tests of the RACFST specimens and found that the ultimate load of RACFST was higher than that of CFST [10]. Tam et al. conducted the finite element analysis of RACFST and found the results were satisfactory [11].

At present, the seismic behavior of the C-RACFST structure mainly focused on the component level and based on experimental research. Xiao et al. conducted the seismic behavior test of six C-RACFST columns and found the excellent deformation and bearing capacity of the CRACFST column [12]. Taking the replacement ratio of 
waste concrete blocks and steel tube thickness as parameters, $\mathrm{Wu}$ et al. studied the seismic behavior of thin-walled steel tube columns filled with waste-concrete blocks or freshconcrete blocks. They found that the columns filled with waste concrete blocks and fresh concrete met the seismic design requirements [13]. Zhang et al. studied the seismic strength and stiffness of the RACFST frame under low-cycle repeated loading [14].

Within the limitations of experimental research method, test conditions, and specimen quantity, few studies have investigated the seismic behavior of new composite components [15-16]. Since finite element analysis is a common method for in-depth and systematic analysis, Xu et al. simulated the seismic behavior of an S-RACFST column and found that the column exhibited satisfactory seismic behavior [17]. Yang simulated the RACFST column beam loading results [18]. In general, previous finite element analysis mainly focused on S-RACFST column, which can provide a reference for evaluating the seismic performance of C-RACFST column in the present work.

In this study, based on the seismic behavior tests on 10 C-RACFST column specimens [19], the design parameters of the specimen were changed to research on the C-RACFST column seismic behavior. The rest of this study is organized as follows: Section 3 describes the design of the specimens and development of calculation model. Section 4 analyzes the results of twenty-three full-scale specimens and evaluates seismic performance indicators, such as hysteresis curve, skeleton curve, ductility coefficient, and energy dissipation capacity. Section 5 provides the relevant conclusions.

\section{Methodology}

\subsection{Design of the specimens}

Many factors affect the seismic behavior of RACFST columns. In this work, the replacement ratio of recycled coarse aggregate $(R)$, steel ratio $(T)$, and axial compression ratio $(N)$ were selected as variation parameters.

The finite element parameters of the 23 full-scale round RACFST column specimens were analyzed based on basic design parameters, namely, inner diameter of $400 \mathrm{~mm}$ for circular steel tube, steel grade of Q345, and slenderness ratio of 30 . The specimen with the single-parameter variation of replacement ratio was named CR0-CR 10 , in which the replacement ratio level difference was $10 \%$, the steel and the axial compression ratios were 0.15 and 0.80 , respectively. The specimen with the single-parameter variation of steel ratio was named CT5-CT30, in which the steel grade level difference was $5 \%$, and the replacement ratio and axial compression ratio were $100 \%$ and 0.80 , respectively. The specimen with the single-parameter variation of the axial compression ratio was named $\mathrm{CN} 0-\mathrm{CN} 10$, in which the level difference was 0.2 ; the replacement ratio and the steel ratio were $100 \%$ and 0.15 , respectively; and the axial compression ratio is $n=N / f_{\mathrm{c}} A_{\mathrm{c}}$, where $N$ is the axial force applied during the test, $f_{\mathrm{c}}$ is the axial compressive strength of RAC, and $A_{c}$ is the section area of the internal RAC.

\subsection{Development of calculation model}

The stress-strain constitutive relationship of the circular steel tube was selected by Abaqus's nonlinear isotropic/kinematic hardening model, and the Bauschinger effect was considered. The constitutive relationship of internal concrete compression was established by Han et al. [20], which is often used in the numerical simulation of CFST. The related study pointed out that under different replacement ratios, the axial compressive strength of RAC showed certain regularity [21]. A compressive constitutive model of the internal RAC of the RACFST specimens with different replacement ratios was established as follows:

$y=2 x-x^{2} \quad(x \leq 1)$

$y=\left\{\begin{array}{ll}1+q\left(x^{0.1 \xi}-1\right) & (\xi \geq 1.12) \\ \frac{x}{\beta(x-1)^{2}+x} & (\xi<1.12)\end{array} \quad(x>1)\right.$

where

$$
\begin{aligned}
& x=\frac{\varepsilon}{\varepsilon_{0}} ; \quad y=\frac{\sigma}{\sigma_{0}} \\
& \sigma_{0}=\left[1+\left(-0.054 \xi^{2}+0.4 \xi\right)\left(\frac{24}{f_{\mathrm{c}, R}^{\prime}}\right)^{0.45}\right] f_{\mathrm{c}, R}^{\prime} \\
& f_{\mathrm{c}, R}^{\prime}=0.8 f_{\mathrm{cu}, R} \\
& f_{\mathrm{cu}, R} / f_{\mathrm{cu}, 0}=-0.4274 R^{3}+0.2493 R^{2}+0.2486 R+1 \\
& \xi=\frac{A_{\mathrm{s}} f_{\mathrm{y}}}{A_{\mathrm{c}} f_{\mathrm{c}, R}} \\
& f_{\mathrm{c}, R} / f_{\mathrm{cu}, 0}=0.19 R^{2}-0.249 R+0.789 \\
& \beta=\left(2.36 \times 10^{-5}\right)^{\left[0.25+(\xi-0.5)^{7}\right]} 3.51 \times 10^{-4} f_{\mathrm{c}}^{\prime 2} \\
& \varepsilon_{0}=\varepsilon_{\mathrm{cc}}+\left[1400+800\left(\frac{f_{\mathrm{c}, R}^{\prime}}{24}-1\right)\right] \xi^{0.2} \quad(\mu \varepsilon) \\
& \varepsilon_{\mathrm{cc}}=1300+12.5 f_{\mathrm{c}, R}^{\prime} \quad(\mu \varepsilon) \\
& \xi^{0.745} \\
& 2+\xi
\end{aligned}
$$

where $f_{\mathrm{c}, R}^{\prime}$ is the axial compressive strength of the cylinder at different replacement ratios, subscript $R$ is the replacement ratio, $f_{\mathrm{cu}, \mathrm{R}}$ is the cube compressive strength with different replacement ratios, $f_{\mathrm{cu}, 0}$ is the cube standard compressive strength with $0 \%$ replacement ratio, and $f_{\mathrm{c}, \mathrm{R}}$ is the axial compressive strength of prisms.

The uniaxial tensile stress-strain relationship of internal RAC was selected according to the current Concrete Structural Design Specification (China, GB50010-2010) because the restraining effect of the external circular steel tube had minimal effect on the tensile properties. The related equation is:

$$
y= \begin{cases}1.2 x-0.2 x^{6} & \left(\varepsilon \leq \varepsilon_{\mathrm{p}}\right) \\ \frac{x}{0.31 \sigma_{\mathrm{p}}(x-1)^{1.7}+x} & \left(\varepsilon>\varepsilon_{\mathrm{p}}\right)\end{cases}
$$


where

$x=\frac{\varepsilon_{\mathrm{c}}}{\varepsilon_{\mathrm{p}}} ; y=\frac{\sigma_{\mathrm{c}}}{\sigma_{\mathrm{p}}}$

where $\sigma_{\mathrm{p}}$ is the peak tensile stress, $\sigma_{\mathrm{p}}=0.26\left(1.25 f_{\mathrm{c}, \mathrm{R}}^{\prime}\right)^{2 / 3}$, and $\varepsilon_{\mathrm{p}}$ is the peak tensile strain, $\varepsilon_{\mathrm{p}}=43.1 \sigma_{\mathrm{p}}(\mu \varepsilon)$.

The concrete plastic damage model was employed into $\mathrm{RAC}$, and the RAC compression and tension damage factor $D$ was calculated as follows [22]:

$D=1-\sqrt{\frac{\sigma}{E_{0} \varepsilon}}$

where $\sigma$ is the stress, $\varepsilon$ is the strain, and $E_{0}$ is the elastic modulus.

The circular steel tube and the RAC adopted the surfaceto-surface contact unit form, and a small slip between the two was allowed. The normal direction was set to hard contact, the interface tangential force was simulated by Coulomb friction model, and the interface friction coefficient between circular steel tube and RAC was 0.60. The circular steel tube and RAC used a 3D solid-state unit called C3D8R, with an eight-node reduced integration format. A displacement boundary condition with a fixed lower end and a free upper end was established, and the geometric boundary conditions were not changed. The vertical load and horizontal displacement were transmitted through the concrete end with high rigidity. The numerical simulation of the seismic behavior of RACFST specimens was carried out by increment-iterated hybrid finite element.

\section{Results and Analysis}

\subsection{Hysteresis curve}

The load $P$-displacement $\Delta$ hysteresis curves of specimens at different replacement ratios are shown in Fig. 1(a). The area of the hysteresis loop of the specimen was large, the hysteresis curve was plump, and the energy dissipation capacity was excellent. With the increase of the replacement ratio, the shape of the hysteresis curve of the specimen became similar as well as the peak-bearing capacities and bearing capacities at each level of cyclic displacement amplitude. The results indicated that the specimen's hysteresis curve did not change when the replacement ratio of recycled coarse aggregate was $0-100 \%$ and the level difference was about $10 \%$.

The hysteresis curves of the specimens at different steel ratios are shown in Fig. 1(b). With the increase of the steel ratio, the area of the hysteresis loop of the specimen under each level of cyclic displacement gradually increased, and the hysteresis curve became plump. The external steel tube had a poor restraining effect on the internal RAC due to the low steel ratio of CT5. In the later stage of the hysteresis curve, the cumulative damage of the specimen increased significantly, the strength attenuation increased, and different hysteresis loops under the same level of cyclic displacement were more discrete. As the steel ratio increased, the hysteresis curve similar to CT5 became weak.

The hysteresis curves of specimens under different axial compression ratios are shown in Fig. 1(c). The hysteresis curve under different axial compression ratios exhibited a full shuttle shape and good energy dissipation capacity. The hysteresis curve of the specimen did not show a falling section even when the axial compression ratios were set to 0 and 0.2 .

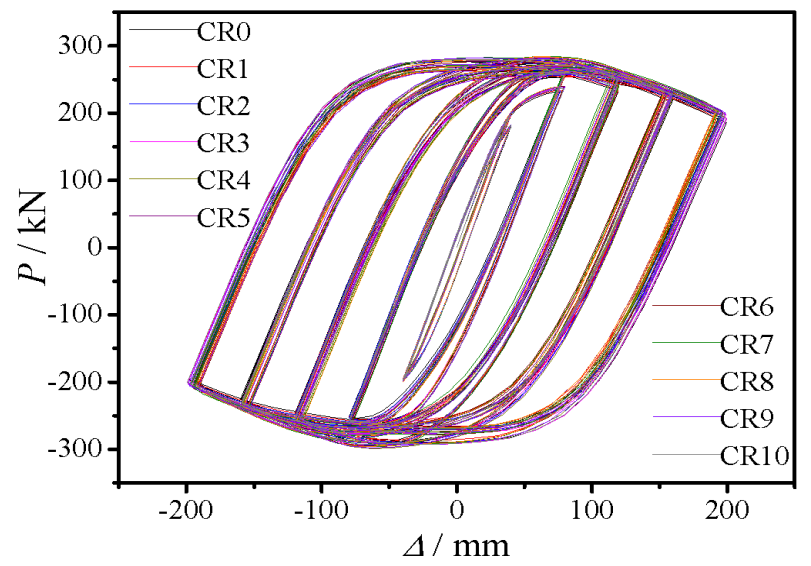

(a) Replacement ratio

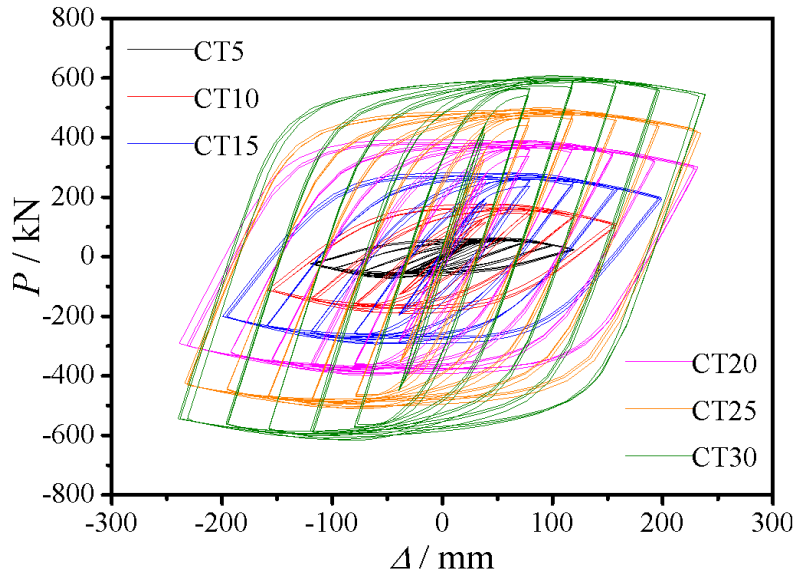

(b) Steel ratio

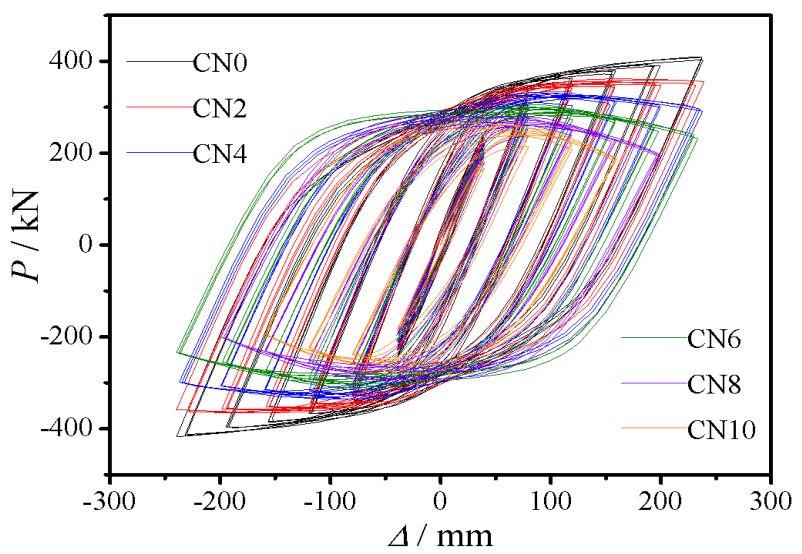

(c) Axial compression ratio

Fig. 1. Hysteresis curves of specimens varied by the single-parameter.

\subsection{Skeleton curve}

The skeleton curves of the specimens under different replacement ratios are shown in Fig. 2 (a). At the elastic stage, the skeleton curves at different replacement ratios were completely coincidental, indicating that the inherent defects of the recycled coarse aggregate replacement ratio had minimal effect on the initial elastic stage stiffness of the test piece. At the peak point, the inherent original defects were evident, resulting in certain difference in the peakbearing capacity. With the increase of the replacement ratio, the variation ranges of the bearing capacity of the specimens were $0.62 \%, 0.45 \%, 0.53 \%, 1.22 \%, 0.47 \%, 0.08 \%, 0.62 \%$, 
$0.92 \%, 0.94 \%$, and $-0.64 \%$, respectively, which were lower than $5 \%$ and within the allowable range of the project. In the falling section, the skeleton curve did not completely coincide, but the fluctuations were unremarkable. In general, increasing the replacement ratio of recycled coarse aggregate exhibited less effect on the skeleton curve of the specimen. According to the seismic strength requirements, C-RACFST can be applied into actual engineering load-bearing structure.

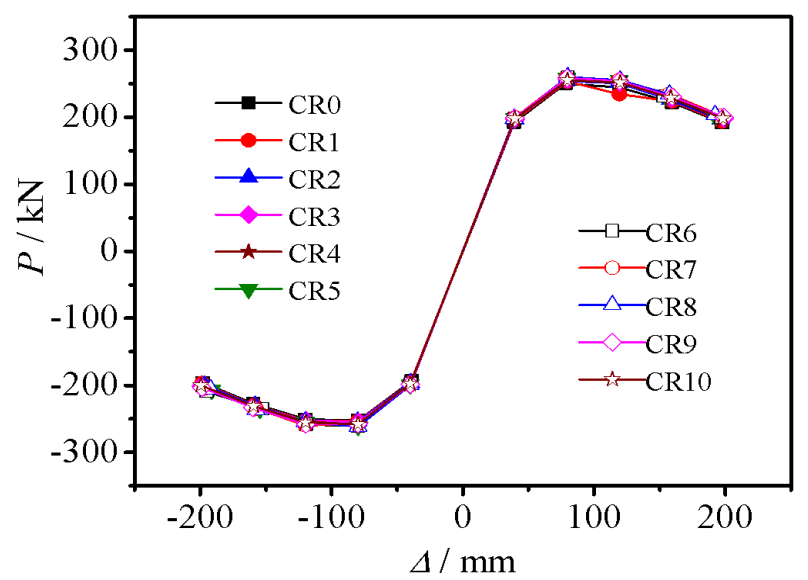

(a) Replacement ratio

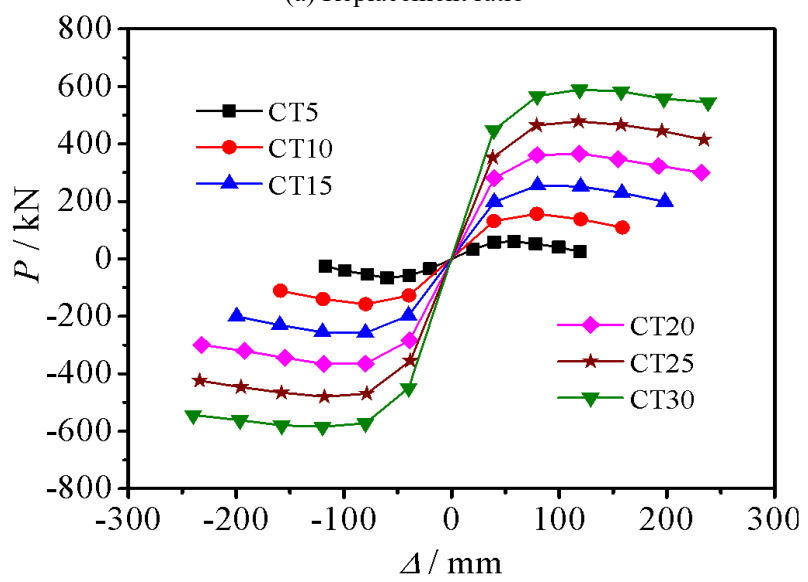

(b) Steel ratio

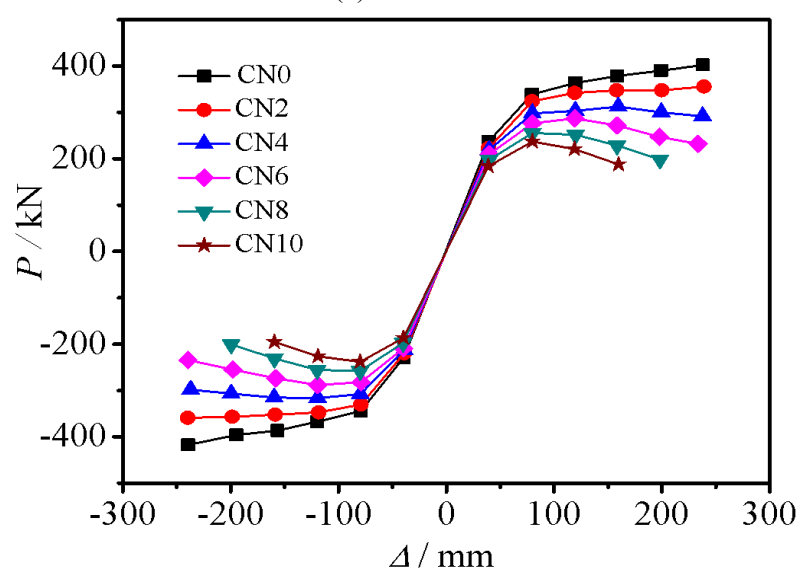

(c) Axial compression ratio
Fig. 2. Skeleton curves of specimens varied by the single-parameter.

The skeleton curves of the specimens under different steel ratios are shown in Fig. 2 (b). The stiffness of the initial elastic stage of the specimen gradually increased with increasing steel ratio and the peak-bearing capacity gradually increased. The variation ranges of the specimen were $148.18 \%, 63.04 \%, 42.38 \%, 31.01 \%$, and $22.53 \%$, respectively. The falling section curve became moderate, and the ductility coefficient became superior.

The skeleton curves of the specimens under different axial compression ratios are shown in Fig. 2 (c). The axial compression ratio exerted minimal effect on the initial elastic phase stiffness of the specimens. The peak-bearing capacity decreased with the increase of the axial compression ratio, and the variation ranges were $-12.83 \%$, $12.18 \%,-8.37 \%,-10.72 \%$, and $-7.35 \%$, respectively. When the axial compression ratio was set to 0.4 , the skeleton curve began to fall. The ductility gradually deteriorated with increasing axial compression ratio.

\subsection{Ductility coefficient}

According to energy equivalent method, the displacement ductility coefficient $(\mu)$ and the characteristic point load and displacement of the specimens at different replacement ratios are shown in Table 1 . The displacement ductility coefficients of all the specimens were approximately 3.00, and the displacement ductility coefficient changed within $5 \%$ with the increase of the replacement ratio. Therefore, when the replacement ratio of recycled coarse aggregate adopted $10 \%$ as the level difference and varied uniformly within $0-100 \%$, the seismic deformation behavior of the fullscale specimens was not affected. Hence, considering the seismic ductility requirements, C-RACFST can be applied to the actual engineering of load-bearing structures.

The displacement ductility coefficient and the characteristic point load and displacement of the specimens under different steel ratios are shown in Table 2. With the increase of the steel ratio, the displacement ductility coefficient increased and the variation amplitude was $26.20 \%, 27.12 \%$, and $22.33 \%$, respectively. When the steel ratio of the specimen was $5 \%$, the displacement ductility coefficient was only 1.87 and the deformation performance was poor. As such, this value is not recommended to be applied in engineering practice.

The displacement ductility coefficient and characteristic point load and displacement of the specimens under different axial compression ratios are shown in Table 3. The displacement ductility coefficient of the specimen gradually decreased with the increase of the axial compression ratio. When the axial compression ratios went from 0.6 to 0.8 until 1.0 , the ductility coefficients of the specimens varied by $9.64 \%$ and $-13.67 \%$, respectively.

Table 1. The characteristic-point load and displacement of specimens with single-parameter variation of replacement ratio.

\begin{tabular}{|c|c|c|c|c|c|c|c|c|}
\hline \multirow{2}{*}{ Number } & \multirow{2}{*}{ Loading direction } & \multicolumn{2}{|c|}{ Yield point } & \multicolumn{2}{|c|}{ Peak point } & \multicolumn{2}{|c|}{ Failure point } & \multirow{2}{*}{$\mu=\Delta_{u} / \Delta_{y}$} \\
\hline & & $\Delta_{\mathrm{y}}(\mathrm{mm})$ & $P_{\mathrm{y}}(\mathrm{kN})$ & $\Delta_{\mathrm{m}}(\mathrm{mm})$ & $P_{\mathrm{m}}(\mathrm{kN})$ & $\Delta_{\mathrm{u}}(\mathrm{mm})$ & $P_{\mathrm{u}}(\mathrm{kN})$ & \\
\hline \multirow{3}{*}{ CR0 } & Positive & 57.24 & 219.80 & 78.33 & 250.25 & 171.15 & 212.72 & 2.99 \\
\hline & Negative & 57.83 & 224.33 & 79.73 & 252.65 & 181.44 & 214.75 & 3.14 \\
\hline & Average & 57.54 & 222.07 & 79.03 & 251.45 & 176.30 & 213.73 & 3.07 \\
\hline \multirow{2}{*}{ CR1 } & Positive & 57.84 & 221.18 & 79.61 & 253.2 & 169.77 & 215.22 & 2.94 \\
\hline & Negative & 57.77 & 221.38 & 79.63 & 252.82 & 175.17 & 214.90 & 3.03 \\
\hline
\end{tabular}


Zhang Xianggang, Wang Shuren, Gao Xiang, He Yongsheng/Journal of Engineering Science and Technology Review 12 (4) (2019) 129 - 135

\begin{tabular}{|c|c|c|c|c|c|c|c|c|}
\hline & Average & 57.81 & 221.28 & 79.62 & 253.01 & 172.47 & 215.06 & 2.98 \\
\hline \multirow{3}{*}{ CR2 } & Positive & 57.40 & 223.00 & 78.85 & 254.10 & 171.53 & 215.99 & 2.99 \\
\hline & Negative & 57.61 & 221.18 & 79.85 & 254.18 & 174.41 & 216.05 & 3.03 \\
\hline & Average & 57.51 & 222.09 & 79.35 & 254.14 & 172.97 & 216.02 & 3.01 \\
\hline \multirow{3}{*}{ CR3 } & Positive & 58.14 & 224.52 & 79.8 & 256.1 & 173.66 & 217.69 & 2.99 \\
\hline & Negative & 57.64 & 223.70 & 79.27 & 254.89 & 175.79 & 216.66 & 3.05 \\
\hline & Average & 57.89 & 224.11 & 79.54 & 255.50 & 174.73 & 217.17 & 3.02 \\
\hline \multirow{3}{*}{ CR4 } & Positive & 58.03 & 224.54 & 79.94 & 257.48 & 171.68 & 218.86 & 2.96 \\
\hline & Negative & 58.62 & 225.51 & 79.14 & 259.75 & 174.58 & 220.79 & 2.98 \\
\hline & Average & 58.33 & 225.03 & 79.54 & 258.62 & 173.13 & 219.82 & 2.97 \\
\hline \multirow{3}{*}{ CR5 } & Positive & 57.99 & 227.08 & 79.2 & 258.73 & 170.28 & 219.92 & 2.93 \\
\hline & Negative & 58.88 & 227.67 & 79.68 & 260.91 & 172.41 & 221.77 & 2.94 \\
\hline & Average & 58.44 & 227.38 & 79.44 & 259.82 & 171.35 & 220.85 & 2.93 \\
\hline \multirow{3}{*}{ CR6 } & Positive & 58.46 & 227.08 & 79.94 & 259.39 & 169.40 & 220.48 & 2.90 \\
\hline & Negative & 58.83 & 228.84 & 79.60 & 260.65 & 172.03 & 221.55 & 2.92 \\
\hline & Average & 58.65 & 227.96 & 79.77 & 260.02 & 170.72 & 221.02 & 2.91 \\
\hline \multirow{3}{*}{ CR7 } & Positive & 57.76 & 228.25 & 79.01 & 258.85 & 175.04 & 220.02 & 3.03 \\
\hline & Negative & 57.83 & 226.78 & 79.57 & 257.99 & 178.43 & 219.29 & 3.09 \\
\hline & Average & 57.80 & 227.52 & 79.29 & 258.42 & 176.74 & 219.66 & 3.06 \\
\hline \multirow{3}{*}{ CR8 } & Positive & 58.43 & 227.67 & 79.98 & 259.92 & 172.66 & 220.93 & 2.96 \\
\hline & Negative & 58.89 & 227.10 & 79.74 & 261.70 & 174.16 & 222.45 & 2.96 \\
\hline & Average & 58.66 & 227.39 & 79.86 & 260.81 & 173.41 & 221.69 & 2.96 \\
\hline \multirow{3}{*}{ CR9 } & Positive & 57.97 & 225.90 & 79.48 & 258.56 & 173.41 & 219.78 & 2.99 \\
\hline & Negative & 58.44 & 230.22 & 79.96 & 258.17 & 176.42 & 219.44 & 3.02 \\
\hline & Average & 58.21 & 228.06 & 79.72 & 258.37 & 174.92 & 219.61 & 3.01 \\
\hline \multirow{3}{*}{ CR10 } & Positive & 57.62 & 224.13 & 79.78 & 255.38 & 174.04 & 217.07 & 3.02 \\
\hline & Negative & 58.71 & 226.10 & 79.80 & 258.05 & 175.42 & 219.34 & 2.99 \\
\hline & Average & 58.17 & 225.12 & 79.79 & 256.72 & 174.73 & 218.21 & 3.01 \\
\hline
\end{tabular}

Note: $\Delta_{\mathrm{y}}$ and $P_{\mathrm{y}}$ represent displacement and load at the yield point, respectively, $\Delta_{\mathrm{m}}$ and $P_{\mathrm{m}}$ denote displacement and load at the peak point, respectively, and $\Delta_{\mathrm{u}}$ and $P_{\mathrm{u}}$ respectively stand for displacement and load at the failure point.

Table 2. The characteristic-point load and displacement of specimens with single-parameter variation of steel ratio.

\begin{tabular}{|c|c|c|c|c|c|c|c|c|}
\hline \multirow{2}{*}{ Number } & \multirow{2}{*}{ Loading direction } & \multicolumn{2}{|c|}{ Yield point } & \multicolumn{2}{|c|}{ Peak point } & \multicolumn{2}{|c|}{ Failure point } & \multirow{2}{*}{$\mu=\Delta_{\mathrm{u}} / \Delta_{\mathrm{y}}$} \\
\hline & & $\Delta_{\mathrm{y}}(\mathrm{mm})$ & $P_{\mathrm{y}}(\mathrm{kN})$ & $\Delta_{\mathrm{m}}(\mathrm{mm})$ & $P_{\mathrm{m}}(\mathrm{kN})$ & $\Delta_{\mathrm{u}}(\mathrm{mm})$ & $P_{\mathrm{u}}(\mathrm{kN})$ & \\
\hline \multirow{3}{*}{ CT5 } & Positive & 39.82 & 57.35 & 57.94 & 60.57 & 78.45 & 51.48 & 1.97 \\
\hline & Negative & 43.07 & 60.10 & 59.78 & 66.32 & 76.20 & 56.37 & 1.77 \\
\hline & Average & 41.45 & 58.73 & 58.86 & 63.44 & 77.33 & 53.93 & 1.87 \\
\hline \multirow{3}{*}{ CT10 } & Positive & 52.23 & 139.21 & 79.48 & 156.38 & 126.52 & 132.92 & 2.42 \\
\hline & Negative & 55.19 & 139.75 & 79.71 & 158.53 & 127.12 & 134.75 & 2.30 \\
\hline & Average & 53.71 & 139.48 & 79.60 & 157.46 & 126.82 & 133.84 & 2.36 \\
\hline \multirow{3}{*}{ CT15 } & Positive & 57.62 & 224.13 & 79.78 & 255.38 & 174.04 & 217.07 & 3.02 \\
\hline & Negative & 58.71 & 226.10 & 79.80 & 258.05 & 175.42 & 219.34 & 2.99 \\
\hline & Average & 58.17 & 225.12 & 79.79 & 256.72 & 174.73 & 218.21 & 3.00 \\
\hline \multirow{3}{*}{ СТ20 } & Positive & 59.23 & 320.45 & 118.83 & 365.54 & 214.05 & 310.71 & 3.61 \\
\hline & Negative & 57.13 & 320.22 & 118.83 & 365.47 & 212.41 & 310.65 & 3.72 \\
\hline & Average & 58.18 & 320.34 & 118.83 & 365.51 & 213.23 & 310.68 & 3.67 \\
\hline \multirow{3}{*}{ CT25 } & Positive & 61.14 & 417.42 & 118.04 & 477.94 & - & - & - \\
\hline & Negative & 60.42 & 417.13 & 117.91 & 479.73 & - & - & - \\
\hline & Average & 60.78 & 417.28 & 117.98 & 478.84 & - & - & \\
\hline \multirow{3}{*}{ СТ30 } & Positive & 61.52 & 513.71 & 118.99 & 588.84 & - & - & - \\
\hline & Negative & 59.72 & 511.69 & 119.73 & 584.56 & - & - & - \\
\hline & Average & 60.62 & 512.70 & 119.36 & 586.70 & - & - & \\
\hline
\end{tabular}

Table. 3. The characteristic-point load and displacement of specimens with single-parameter variation of axial compression ratio.

\begin{tabular}{|c|c|c|c|c|c|c|c|c|}
\hline \multirow{2}{*}{ Number } & \multirow{2}{*}{ Loading direction } & \multicolumn{2}{|c|}{ Yield point } & \multicolumn{2}{|c|}{ Peak point } & \multicolumn{2}{|c|}{ Failure point } & \multirow[b]{2}{*}{$\boldsymbol{\mu}$} \\
\hline & & $\Delta_{\mathrm{y}}(\mathrm{mm})$ & $P_{\mathrm{y}}(\mathrm{kN})$ & $\Delta_{\mathrm{m}}(\mathrm{mm})$ & $P_{\mathrm{m}}(\mathrm{kN})$ & $\Delta_{\mathrm{u}}(\mathrm{mm})$ & $P_{\mathrm{u}}(\mathrm{kN})$ & \\
\hline \multirow{3}{*}{$\mathrm{CN} 4$} & Positive & 69.90 & 278.55 & 159.54 & 312.55 & - & - & - \\
\hline & Negative & 66.16 & 278.00 & 159.71 & 315.07 & - & - & - \\
\hline & Average & 68.03 & 278.28 & 159.63 & 313.81 & - & - & - \\
\hline \multirow{3}{*}{ CN6 } & Positive & 64.24 & 249.69 & 119.17 & 286.95 & 203.76 & 243.91 & 3.17 \\
\hline & Negative & 63.23 & 252.05 & 119.17 & 288.13 & 219.06 & 244.91 & 3.46 \\
\hline & Average & 63.74 & 250.87 & 119.17 & 287.54 & 211.41 & 244.41 & 3.32 \\
\hline \multirow{3}{*}{ CN8 } & Positive & 57.62 & 224.13 & 79.78 & 255.38 & 174.04 & 217.07 & 3.02 \\
\hline & Negative & 58.71 & 226.10 & 79.80 & 258.05 & 175.42 & 219.34 & 2.99 \\
\hline & Average & 58.17 & 225.12 & 79.79 & 256.72 & 174.73 & 218.21 & 3.00 \\
\hline \multirow{3}{*}{$\mathrm{CN} 10$} & Positive & 56.80 & 207.81 & 79.74 & 237.23 & 143.19 & 201.65 & 2.52 \\
\hline & Negative & 57.10 & 208.80 & 79.98 & 238.48 & 152.09 & 202.71 & 2.66 \\
\hline & Average & 56.95 & 208.31 & 79.86 & 237.86 & 147.64 & 202.18 & 2.59 \\
\hline
\end{tabular}




\subsection{Energy dissipation capacity}

Equivalent viscous damping coefficient $\left(h_{\mathrm{e}}\right)$ was used to evaluate the energy dissipation capacity of the specimen. The he values of the specimens with different replacement ratios are shown in Table 4.

The energy dissipative coefficient of the full-scale specimen gradually increased with the increase of the cyclic displacement. At the end of loading, the energy dissipative coefficient of the specimen reached approximately 0.650 . The energy dissipative coefficient under the same cyclic displacement did not change much (the variation range was within $5 \%$ ) with the increase of the replacement ratio. The seismic deformation behavior of the full-scale specimens was not affected when the replacement ratio of recycled coarse aggregate adopted $10 \%$ as the level difference and varied uniformly within $0-100 \%$. Applying C-RACFST to actual engineering of load-bearing structures is feasible given the seismic ductility requirements.

Table 4. The $h_{\mathrm{e}}$ for specimens with single-parameter variation of replacement ratio.

\begin{tabular}{c|c|c|c|c|c}
\hline Number & $\boldsymbol{\Delta}$ & $\mathbf{2 \Delta}$ & $\mathbf{3 \Delta}$ & $\mathbf{4 \Delta}$ & $\mathbf{5 \Delta}$ \\
\hline CR0 & 0.059 & 0.207 & 0.366 & 0.502 & 0.665 \\
CR1 & 0.059 & 0.205 & 0.366 & 0.490 & 0.669 \\
CR2 & 0.058 & 0.202 & 0.366 & 0.499 & 0.648 \\
CR3 & 0.058 & 0.202 & 0.361 & 0.491 & 0.650 \\
CR4 & 0.059 & 0.203 & 0.354 & 0.499 & 0.629 \\
CR5 & 0.058 & 0.206 & 0.362 & 0.482 & 0.626 \\
CR6 & 0.057 & 0.198 & 0.347 & 0.483 & 0.627 \\
CR7 & 0.058 & 0.199 & 0.366 & 0.472 & 0.632 \\
CR8 & 0.056 & 0.199 & 0.353 & 0.474 & 0.625 \\
CR9 & 0.058 & 0.201 & 0.350 & 0.498 & 0.643 \\
CR10 & 0.059 & 0.209 & 0.355 & 0.489 & 0.652 \\
\hline
\end{tabular}

The $h_{\mathrm{e}}$ values of the specimens under different steel ratios are shown in Table 5. With the increase of the cyclic displacement, the energy dissipative coefficient of the specimens with different steel ratios increased gradually. When the steel ratios were $10 \%, 15 \%, 20 \%, 25 \%$, and $30 \%$, the energy dissipative coefficient decreased gradually at the same stage of cyclic displacement, because the lower the steel ratio of the specimen is, the closer it is to yield and failure at the same cyclic displacement. As a result, the deformation behavior is released intensely and the energy dissipation ability becomes stronger. When the steel ratio was $5 \%$, the energy dissipation coefficient under each stage of cyclic displacement was smaller than other steel ratios because of the small cyclic displacement amplitude bearing capacity and hysteresis loop area and weak energy dissipation.

Table 5. The $h_{\mathrm{e}}$ for specimens with single-parameter variation of steel ratio.

\begin{tabular}{c|c|c|c|c|c|c}
\hline Number & $\boldsymbol{\Delta}$ & $\mathbf{2 \Delta}$ & $\mathbf{3 \Delta}$ & $\mathbf{4 \Delta}$ & $\mathbf{5 \Delta}$ & $\mathbf{6 \Delta}$ \\
\hline CT5 & 0.066 & 0.093 & 0.183 & 0.311 & 0.559 & 1.107 \\
CT10 & 0.069 & 0.240 & 0.417 & 0.687 & - & - \\
CT15 & 0.025 & 0.203 & 0.389 & 0.529 & 0.617 & 0.746 \\
CT20 & 0.052 & 0.211 & 0.343 & 0.449 & 0.541 & 0.622 \\
CT25 & 0.042 & 0.205 & 0.340 & 0.428 & 0.498 & 0.564 \\
CT30 & 0.038 & 0.208 & 0.337 & 0.417 & 0.476 & 0.526 \\
\hline
\end{tabular}

The $h_{\mathrm{e}}$ values of the specimens under different axial compression ratios are shown in Table 6. The energy dissipative coefficient of the specimens gradually increased with the increase of the cyclic displacement. With the increase of the axial compression ratio, the energy dissipative coefficient of each specimen increased gradually under the same cyclic displacement, mainly because the specimen with a large axial compression ratio was earlier involved into the yield and failure stages.

Table 6. The $h_{\mathrm{e}}$ for specimens with single-parameter variation of axial compression ratio.

\begin{tabular}{c|c|c|c|c|c|c}
\hline Number & $\boldsymbol{\Delta}$ & $\mathbf{2 \Delta}$ & $\mathbf{3 \Delta}$ & $\mathbf{4 \Delta}$ & $\mathbf{5} \boldsymbol{6}$ & $\mathbf{6 \boldsymbol { \Delta }}$ \\
\hline CN0 & 0.052 & 0.188 & 0.283 & 0.309 & 0.338 & 0.325 \\
CN2 & 0.051 & 0.183 & 0.289 & 0.346 & 0.372 & 0.389 \\
CN4 & 0.052 & 0.177 & 0.307 & 0.377 & 0.431 & 0.472 \\
CN6 & 0.053 & 0.190 & 0.318 & 0.424 & 0.505 & 0.605 \\
CN8 & 0.059 & 0.209 & 0.355 & 0.489 & 0.652 & - \\
CN10 & 0.067 & 0.226 & 0.390 & 0.580 & - & - \\
\hline
\end{tabular}

\section{Conclusions}

The seismic behaviors of 23 full-scale circular RACFST column specimens were analyzed by finite element method within the variation range of design parameters. The main conclusions are as follows:

(1) The hysteresis and skeleton curves of full-scale specimens are not affected when the replacement ratio of recycled coarse aggregate adopts $10 \%$ as the level difference and varies uniformly within $0-100 \%$. The variations in displacement ductility coefficient and energy dissipation coefficient are less than 5\%. Applying C-RACFST to actual engineering of load-bearing structures is feasible given the seismic ductility requirements.

(2) With the increase of the steel ratio, the hysteresis curve becomes plumper, the strength of the CT5 specimen decreases seriously in the later stage, the stiffness increases gradually in the initial elastic stage, the peak bearing capacity increases gradually, and the displacement ductility coefficient increases gradually. The deformation behavior of CT5 is poor, so it is not recommended to be applied in engineering practice.

(3) The hysteresis curves of the specimens at different axial compression ratios show a full shuttle shape. When the axial compression ratios are 0 and 0.2 , the hysteresis curve does not have a falling section. With the increase of the axial compression ratio, the stiffness of the initial elastic stage is less affected, the peak bearing capacity decreases, the ductility decreases, and the energy dissipative coefficient of each specimen increases gradually at the same stage cyclic displacement.

Circular, square, and rectangular sections are commonly used in RACFST structures. Ellipses and polygons are also used in engineering. The proposed finite element model is only applicable to circular sections. A finite element model of the seismic performance of the RACFST structure will be further developed and verified for other sections.

\section{Acknowledgements}

This work was financially supported by the National Natural Science Foundation of China (51774112, 51474188), the Doctoral Fund of Henan Polytechnic University (B2015-67), and Key Scientific Research Project Plan for Colleges and Universities in Henan Province (20A560012).

This is an Open Access article distributed under the terms of the Creative Commons Attribution License 


\section{References}

1. Silva, R. V., Brito, J. D., Dhir, R. K., "Properties and composition of recycled aggregates from construction and demolition waste suitable for concrete production". Construction and Building Materials, 65, 2014, pp. 201-217.

2. El-Hassan, H., Kianmehr, P., Zouaoui, S., "Properties of pervious concrete incorporating recycled concrete aggregates and slag". Construction and Building Materials, 212, 2019, pp. 164-175.

3. Huang, Y. J., Xiao, J. Z., Zhang, C. H., "Theoretical study on mechanical behavior of steel confined recycled aggregate concrete”. Journal of Constructional Steel Research, 76, 2012, pp. 100-111.

4. Chen, Z. P., Xu, J. J., Chen, Y. L., Lui, E.M., "Recycling and reuse of construction and demolition waste in concrete-filled steel tubes: A review". Construction and Building Materials, 126, 2016, pp. 641660 .

5. Al-Eliwi, B. J. M., Ekmekyapar, T., Al-Samaraie, M. I. A and Dogru, M. H., "Behavior of reinforced lightweight aggregate concretefilled circular steel tube columns under axial loading". Structures, 16, 2018, pp. 101-111.

6. Nabati, A., Ghanbari-Ghazijahani, T., Ng, C. T., "CFRP-reinforced concrete-filled steel tubes with timber core under axial loading". Composite Structures, 217, 2019, pp. 37-49.

7. Pons, D., Espinos, A., Albero, V., Romero, M. L., "Numerical study on axially loaded ultra-high strength concrete-filled dual steel columns". Steel and Composite Structures, 26 (6), 2018, pp. $705-$ 717.

8. Choi, S., "Compressive performance of $50 \mathrm{MPa}$ concrete filled square and circular steel tubes (CFT) columns using recycled aggregate". Journal of the Korean Society for Advanced Composite Structures, 9(2), 2018, pp. 72-80.

9. Abed, F., AlHamaydeh, M., Abdalla, S., "Experimental and numerical investigations of the compressive behavior of concrete filled steel tubes (CFSTs)". Journal of Constructional Steel Research, 80, 2013, pp. 429-439.

10. Mohanraj, E. K., Kandasamy, S. and Malathy, R., "Behaviour of steel tubular stub and slender columns filled with concrete using recycled aggregates". Journal of The South African Institution of Civil Engineering, 53(2), 2011, pp. 31-38.

11. Tam, V. W. Y., Wang, Z. B., Tao, Z., "Behaviour of recycled aggregate concrete filled stainless steel stub columns". Materials and Structures, 47(1-2), 2014, pp. 293-310.
12. Xiao, J. Z., Huang, Y. J., Sun, Z. H., "Seismic behavior of recycled aggregate concrete filled steel and glass fiber reinforced plastic tube columns". Advances in Structural Engineering, 17(5), 2014, pp. 693-707.

13. Wu, B., Zhao, X. Y., Zhang, J. S., Yang, Y., "Cyclic testing of thinwalled circular steel tubular columns filled with demolished concrete blocks and fresh concrete". Thin-Walled Structures, 66, 2013, pp. 50-61.

14. Zhang, X.G., Yang, J. H., Zhang, Y. Z., Gao, X., "Seismic strength and stiffness for recycled aggregate concrete-filled steel tube frame". Advances in Civil Engineering, (1), 2019, pp. 1-11.

15. Wang, S. R., Xiao, H. G., Cao, C., Zou, Z. S., Liu, X. L., "Simulation verification analysis of anchoring characteristics of transverse rib steel bar during pull-out test". Dyna, 91(5), 2016, pp. 548-553.

16. Wang, S. R., Xiao, H. G., Zou, Z. S., Cao, C., Wang, Y. H., Wang, Z. L., "Mechanical performances of transverse rib bar during pullout test". International Journal of Applied Mechanics, 11(5), 2019, pp. 1950048: 1-15.

17. Xu, J. J., Chen, Z. P., Xue, J. Y., Chen, Y. L., Zhang, J. T. "Simulation of seismic behavior of square recycled aggregate concrete-filled steel tubular columns". Construction and Building Materials, 149, 2017, pp. 553-566.

18. Yang, Y. F., "Modelling of recycled aggregate concrete-filled steel tube (RACFST) beam-columns subjected to cyclic loading". Steel and Composite Structures, 18(1), 2015, pp. 213-233.

19. Zhang, X.G., Chen, Z. P., Xue, J. Y., Su, Y. S. "Test and finite element analysis of seismic performance for recycled aggregate concrete filled circular steel tube column". Journal of Basic Science and Engineering, 24 (3), 2016, pp. 582-594.

20. Han, L. H., Yao, G. H., Zhao, X. L., "Tests and calculations for hollow structural steel (HSS) stub columns filled with selfconsolidating concrete (SCC)". Journal of Constructional Steel Research, 61(9), 2005, pp. 1241-1269.

21. Zhang, X. G., Wang, S. R., Gao, X., "Mechanical properties of recycled aggregate concrete subjected to compression test". Journal of Engineering Science and Technology Review, 11(6), 2018, pp. 20-25.

22. Yu, T. Q., Qian, J. C., “Theory and application of damage”. Beijing: National Defence Industry Press, China, 1993, pp. 15-19. 